\section{The Impact of Personal Features of Research Participants on the Adequacy of Personal Success Forecast in Different Test Situations}

I.G. Makarevskaya

At the present time, a number of scientists are considering a psychological study "from the position of the subject", as an experimentally organized activity of the subject to perform a specific behavioral task. In this case, a person is included in the study as an integral object, and, consequently, the organization of research requires the consideration of the basic psychological regularities that determine the behavior of the individual in conditions appropriate to the situation of measurement.

The results of all psychological measurements are mediated by reciprocal relationships between the measured property, method, procedure and subject of measurement. Most important for a psychodiagnostician is information about situational peculiarities of behavioral and cognitive reactions of people in various test situations.

V.N.Druzhinin highlighted the need to consider ecological validity, emphasizing that using standard psychodiagnostic procedures in different test situations may cause completely different interpretations of the results. Ecological validity, as test validity with reference to property measured within a specific situation, in our view, involves the need to answer the questions - how is the test situation itself represented in the consciousness of the research participant and how authentic are the research results as viewed by the research participant

We compared different measurement cases "situation of examination" and "situation of client", and classical and adaptive test situations. The measured property were specific capabilities of 150 research participants
We also studied personal features of participants using the methodologies: J.Rotter Locus of Control, Rusalov Structure of Temperament Questionnaire, Spielberger State-Trait Anxiety Inventory and McCrae and Costa Five-Factor Personality Inventory. The following research objectives were set:

- analyze the adequacy of a personalized success forecast in various testing situations:

to study the features of probabilistic forecasting of the success of the activity of the subjects taking into account the specificity of the emotional response to tests of achievements (situational anxiety);

- to determine the specific components of the personal forecast when testing achievements in the "client situation" and "examination situation".

The adequacy and focus of the inadequacy of the personal forecast of success in the situation of testing achievements were studied by us through revealing the shift between the actual result obtained by the test subject during the testing and the predicted assessments determined by the test subjects before the testing begins.

As a result, several groups of subjects were singled out: subjects whose personal prognosis for success in the testing situation corresponded to the actual results obtained; test subjects predicting a result corresponding to lower values than those actually obtained; and subjects, whose prognosis of success corresponded to the results greater than they were received in reality.
Table. Distribution of subjects depending on the adequacy of a personal forecast of success in the "examination situation" and in the "client situation".

\begin{tabular}{|l|c|c|}
\hline & $\begin{array}{c}\text { "The } \\
\text { situation } \\
\text { of } \\
\text { expertise" }\end{array}$ & $\begin{array}{c}\text { "The situation } \\
\text { of the client" }\end{array}$ \\
\hline $\begin{array}{l}\text { Adequate } \\
\text { forecast }\end{array}$ & $\begin{array}{c}79 \text { people. } \\
(52,7 \%)\end{array}$ & $\begin{array}{c}35 \text { people. } \\
(23,3 \%)\end{array}$ \\
\hline $\begin{array}{l}\text { Overstating the } \\
\text { forecasted } \\
\text { result in relation } \\
\text { to the real }\end{array}$ & $\begin{array}{c}40 \text { people } \\
(26,7 \%)\end{array}$ & $\begin{array}{c}54 \text { people. } \\
(36 \%)\end{array}$ \\
\hline $\begin{array}{l}\text { Underestimation } \\
\text { of the projected } \\
\text { result in relation } \\
\text { to the real }\end{array}$ & $\begin{array}{c}31 \text { people. } \\
(20,6 \%)\end{array}$ & $\begin{array}{c}61 \text { people } \\
(40,7 \%)\end{array}$ \\
\hline
\end{tabular}

Thus, there is a certain specificity of forecasting success in the "situation of expertise" and "client situation". In the "client situation", a larger number of subjects gives an adequate prediction about a possible successful outcome of the testing situation, in the "expert situation" most of the subjects demonstrate a tendency to underestimate the predicted result compared to the real one. Mann-Whitney U-test statistical processing demonstrated considerable differences in the adequacy of personal success forecast in a "situation of examination" and "situation of client" $(p<0,001)$
In a "situation of examination" the participants forecast possible failure of the activity more often than in a "situation of client". Comparison of adaptive and classical test situations showed that in adaptive test situation the participants are considerably more optimistic in the forecast regarding the test result $(p<0,005)$.

The adequacy of personal success forecast in different test situations is much affected by such personal features of participants as: trait anxiety $(p<0,001)$, neuroticism $(p<0,02)$, extraversion $(p<0,03)$, manifestation of guilt feeling $(p<0,04)$, internality $(p<0,01)$, activity level $(p<0,03)$ and ergicity $(p<0,001)$.

Knowing specific components of personal success forecast made by participants with different personal features in different test situations, we will have a more clear understanding of the impact of the measurement procedure context on the efficiency of different psychodiagnostic tools. 